\section{Mental health and "the Troubles" in Northern Ireland: implications of civil unrest for health and wellbeing}

\section{C Kelleher}

\section{Mental health and social capital}

$M$ ental ill health is the new global epidemic and its wider determinants of great social significance. ${ }^{1}$ In this issue O'Reilly and Stevenson present findings from Northern Ireland indicating that the prolonged civil conflict there seems to have had an adverse effect on the mental health and wellbeing of citizens. ${ }^{2}$ The study is of interest for several reasons. Firstly, Northern Ireland is an internationally famous example of a longstanding violent political conflict apparently resolved by a major peace initiative over the past five years. ${ }^{3}$ As there are many such political trouble spots globally, the immediate and longer term public health implications are always of interest. Secondly, the specific independent measure reported in this study, the GHQ-12, is a well validated indicator of mental health status and the interpretation of its significance is important. ${ }^{1}$ Thirdly, internationally both the social variations and health promotion literature have focused increasingly on concepts of social capital and cohesion in interpreting how macrosocial processes might affect individual and community wellbeing. ${ }^{4}$ In this context the breakdown of community relations to the point of outright conflict, particularly in circumstances of material disadvantage, is highly pertinent to our interpretation of this paper.

The data O'Reilly and Stevenson present are based on the Northern Ireland Health and Wellbeing survey of 1997. In assessing the impact at area and personal level of "the Troubles", careful account is taken of religious affiliation, socioeconomic status, long term illness or disability, major life event stressors, and available social support. Their findings show an independent effect on GHQ-12 caseness score of personal and area based exposures to the Troubles, even when these various socioeconomic indicators are taken into account. Notwithstanding this, it is also true that those living in disadvantaged circumstances were much more likely to rate an impact of the Troubles on their lives. For confidentiality purposes, it was not possible to link individual level data directly to specific postal areas, which might have afforded a more in depth multilevel analysis on the directionality of this phenomenon, including other ecological level contextual data. We cannot therefore say with certainty how precisely the effect of the Troubles is mediated at individual level.

Many individuals and families since 1968 were directly affected by material or personal loss. More indirectly, prolonged exposure to fear of injury, death, or bereavement might well lead to anxiety and distress in vulnerable people, even if in statistical terms their absolute risk exposure is small. These are the two main pathways proposed by O'Reilly and Stevenson. ${ }^{2}$ The material disadvantage and restriction of amenities associated with the conflict might have a role in specifically vulnerable communities. It is also possible that the hostility and distrust inherent in the conflict might affect individuals' sense of wellbeing and control, an argument more in keeping with the social capital literature. ${ }^{45}$ Though these data were collected in 1997 at the outset of the peace process it should be noted that paramilitary style shootings and beatings continue at community level and arguably have little if anything to do with the larger political agenda. This holds resonance for the debates in the general health inequalities literature, where prevalence of violent crime, particularly related to firearms, has been associated with increased mistrust, personal vulnerability, and increased rates of mental ill health. Hseih and Pugh conducted a metanalysis of available literature in 1993 that emphasises the role of poverty and relative disadvantage in predicting violent crime. ${ }^{6}$ Similarly Kennedy et al relate firearm associated crime to measures of income inequality and social mistrust in the United States. ${ }^{7}$ Understanding conflict they assert requires an appreciation of wider material and psychosocial determinants than the immediate availability of weapons.

Ireland provides specific context in deconstructing how and whether national and local politics might affect health. The island of Ireland has been partitioned since 1922, Northern Ireland remaining as part of the United Kingdom with England, Scotland, and Wales and Southern Ireland now an independent republic. The two jurisdictions share many common characteristics and there has historically been high migration out of Ireland, that diaspora having a poorer health profile over at least two generations, based on present evidence. ${ }^{89}$ This is explained partly, but not completely by social disadvantage and adverse lifestyles. Both North and South of Ireland have relatively poor mortality patterns compared with other European neighbours, with high rates of cardiovascular disease and of some cancers. ${ }^{10}$ Findings from the PRIME study of cardiovascular disease in France and Northern Ireland indicate that the differences are not explicable by traditional risk factors. ${ }^{11}$ There is some evidence that adverse Type A characteristics are more prevalent in Northern Ireland. ${ }^{12}$ However, genetic predisposition, perhaps mediated through diet is another suggested explanation. ${ }^{11}$

Where North and South diverge, interestingly, is in self rated measures, as seen in this study by O'Reilly and Stevenson. ${ }^{2}$ In fact several studies of self rated health, satisfaction with life, and GHQ-2 scores show that those in the Republic of Ireland have paradoxically positive self ratings, whereas GHQ-12 scores in the North are worse than in all their neighbouring countries. ${ }^{10}$ We have argued previously that the positive social capital in the South has not translated into better objective patterns of morbidity and mortality however and that patterns of material disadvantage must also be taken into account. ${ }^{10}$

Until recent times Northern Ireland was comparatively more industrialised and affluent than the South. Many large employers, often associated with one religious persuasion have scaled down or disappeared. Economic gains have been higher in the South for a variety of reasons, including its status as a member state of the European Union. At least one adverse impact of "the Troubles" has been the hampering of economic investment in the North so that it is in many respects the most disadvantaged area in the United Kingdom. Sociodemographic factors expressed partially through religious affiliation have played a continuing part. Catholics tend to be more deprived than Protestants and to have poorer health profiles but the religious difference disappears when socioeconomic circumstances are taken into account, as O'Reilly and Stevenson have shown previously. ${ }^{13}$

This divided society has its roots in Irish political history. In simplistic terms for the general reader, the root of the "Irish Question" over several centuries has been the wish of Nationalists, mainly 
but not exclusively of a Roman Catholic tradition, to become independent of the United Kingdom and the wish of Unionists, again mainly but not exclusively of Protestant tradition, (and in a majority in Northern Ireland since partition in 1922) to remain in the United Kingdom. This is not a simple sectarian issue however and indeed it is possible to legitimately hold either point of view without resorting to violence. Furthermore, early Nationalist Republicans were often nonconformists inspired by the enlightenment tradition and the revolutions in France and the USA. What matters to some analysts is the economic basis for this conflict, as Ireland traditionally has been much poorer than the rest of the United Kingdom, (with the arguable exception of Northern Scotland) and suffered a devastating famine period in the mid-19th century. Alexis De Tocqueville, for instance, who found much to praise in the emerging Republic of the USA, was scarified by the disadvantage of the Irish peasant. ${ }^{14}$ As that peasantry was overwhelmingly Catholic and the Protestant plantation immigrants into the country over the past three centuries were likely to take up land holdings, the fundamental part played by relative disadvantage in understanding the Nationalist politics of Ireland is critical.

What then is the directionality of these processes? Is material disadvantage a root cause or a result of ethnic, racial conflicts? The immediate probable explanation for the adverse mental health profile in Northern Ireland is as a consequence of the conflict in itself rather than the wider determining history, not least because North and South diverge so sharply in mental health indicators. The psychosocial hypothesis as a mediating influence in relative disadvantage is an attractive possibility but the issues are complex and more direct evidence of an independent effect is required, particularly in assessing disease specific pathways.

We do not need to understand the precise mechanisms at a social scientific level to make a general public policy point that access to weaponry leads to injury and death, particularly in vulnerable, disadvantaged communities. Exposure to that risk causes mental distress that can be clinically significant. Reducing access to weaponry requires political solutions by bringing people to the point of negotiation. Both top-down and bottom-up strategies are needed to achieve this. It seems reasonable to suggest however that getting the gun out of Irish politics was seen to be the critical first start to breaking the vicious circle of violence, ${ }^{3}$ just as getting the gun out of American ghettos might have the same cogency in the long run, in very different sociopolitical circumstances.

Finally what action may be taken at community or health service delivery level? The authors indicate that clinical significance of GHQ caseness scores at a population level are disputed. They also produce evidence that actual health service utilisation has not increased. ${ }^{2}$ Whether therefore the solution lies in treating the population as potential patients or attempting to instigate community level changes is the question. In this respect several initiatives have been taken in the past few years at crossborder level and community levels to try to reduce barriers around stigma related to mental illness and also to foster more health promoting community relations. These have been reviewed recently for the Institute for Cross-Border Studies. ${ }^{1}$ While the initiatives are admirably motivated, many are at an early stage and few are systematic enough to render measurable outcome data, which is indeed an exciting challenge for the mental health promotion literature generally.

$J$ Epidemiol Community Health 2003;57:474-475

\section{Author's affiliations}

C C Kelleher, Department of Public Health Medicine and Epidemiology, Faculty of Medicine, Earlsfort Terrace, University College, Dublin 2, Eire

Correspondence to: Professor C C Kelleher; cecily.kelleher@ucd.ie

\section{REFERENCES}

1 Barry M, Friel S, Dempsey C, et al. Promoting mental health and social well-being: cross-border opportunities and challenges. A report for the Centre for Cross-Border Studies and the Institute of Public Health in Ireland. Armagh: 2002

2 O'Reilly D, Stevenson M. Mental health in Northern Ireland: have "the Troubles" made it worse? J Epidemiol Community Health 2003:57:488-92.

3 Mitchell G. Making peace work. The inside story of the Good Friday Agreement. London: Heinemann, 1999.

4 Wilkinson RG. Unhealthy societies. The afflictions of inequalities. London: Routledge, 1996.

5 Kawachi I, Kennedy BP. The health of nations: why inequality is harmful to your health. New York: The New Press, 2002.

6 Hseih CC, Pugh MD. Poverty, income inequality and violent crime. In: Kawachi I, Kennedy BP, Wilkinson RG, eds. The society and population health Reader (1). Income inequality and health. New York: The New Press, 1999:278-96.

7 Kennedy BP, Kawachi I, Prothrow-Stith D, ef al. Social capital, income inequality and firearm violent crime. In: Kawachi I, Kennedy BP, Wilkinson RG, eds. The society and population health reader (1). Income inequality and health. New York: The New Press, 1999:320-35.

8 Harding S, Balarajan R. Patterns of mortality in second-generation Irish living in England and Wales: longitudinal study. BN 1996:312:1389-92.

9 Kelleher CC, Lynch JW, Harper S, et al. Hurling alone? How social capital failed to save the Irish from cardiovascular disease in the United States of America. Am J Public Health (in press).

10 Kelleher C, Timoney A, Friel S, et al. Indicators of deprivation, voting patterns and health status at area level in the Republic of Ireland. J Epidemiol Community Health 2002;56:36-44

11 Graille V, Ferrieres J, Evans A, et al. Associations between claasical cardiovascular risk factors and coronary artery disease in two countries at contrasting risk for myocardial infarction: the PRIME study. Int J Cardiol 200;74:191-8.

12 Sykes DH, Haertel U, Gostautas A, et al. The Framingham Type-a behaviour pattern and coronary heart disease in 3 countries-a cross-cultural comparison. Int J Epidemiol 1992;21:1081-9.

13 O'Reilly D, Stevenson M. Indicators of deprivation and ill-health in the two communities in Northern Ireland. J Public Health Med 1998;20:161-8.

14 Larkin E, ed. Alexis de Tocqueville's journey to Ireland July-August 1835. Washington: Catholic University of America Press, 1990. 
Statistics

\section{Routine statistics: more interest is needed}

\section{F Paccaud}

\section{Public health also depends on information systems}

$\mathrm{T}$ he World Health Organisation's annual report of the year $2000^{1}$ illustrated at least two features of health information systems at present. One is that the public is eager to compare, evaluate, and discuss health topics using "information products" such as quantitative figures, rankings, and the like. By providing information on health results achieved in each country and on the levels of resources invested, the WHO was able to trigger off a debate of unprecedented vigour.

However, this report also produced a vivid example on the frailty of the data on which most health information is based. As a matter of fact, the WHO study is based on scanty data: a reasonable system of vital statistics is still missing in large areas of the world, and data on the activities in health services are rudimentary in many countries, even in the richest parts of the world. Even a novel concept, like the one brilliantly developed in the WHO report, cannot overcome basic failures. Expectedly, but sadly, a large part of the discussion on this WHO report has been about the (poor) information system rather than on the (poor) performance of health systems.

Part of this problem is investigated by Unal and colleagues in this issue. ${ }^{2}$ They explored systematically the existing data sources currently used in the UK to monitor and evaluate coronary heart diseases (CHD) and related aspects of prevention and care. With a standardised tool, the authors review the sources related to persons and to treatments, as well as data sources on classic risk factors for cardiovascular diseases. This study is refreshing for readers embarked in the daily utilisation of routine statistics-that is, for most of those people working in public health. It provides substantial information for UK researchers and practitioners: they now have access to a relevant evaluation of the databases available in the field of CHD.

It is also refreshing for the non-UK reader: it reminds everybody that we have to take care of the health information system if we want to develop public health strategies. Indeed, the situation is distressing in many countries, and in most areas of public health. Because of the recent and huge development of electronic tools (from data storage to data transmission and the ability to perform complex statistical analysis), there is the vague belief that the health information is performing increasingly well. This reveals a common confusion, just as technical feats of the television tend to mask the intellectual poverty of (most) programmes.

Unal et al typically show that a large amount of data related to $\mathrm{CHD}$ is available, even if many data sources must be looked for outside the health system. Although the United Kingdom might enjoy a richer set of data sources than others, a similar profusion is observed in most developed countries. However, the authors identify substantial problems, which most practitioners and researchers will easily recognise. One is related to the difficulty to analyse trends because of the irresolute character of many surveys, and also because of the continuous changes in definition of items, formulation of questions, etc.

These changes are clearly inappropriate when studying slow secular changes in the pattern of risk factors. The problem is partly related to the fact that, for many data, the data collection is defined outside the department of health: data on physical activity for example might be collected by the statistical unit of the department of transport, or data on housing by the social statistics. A practical proposal, thus, is to set up coordinating mechanisms within the official statistics in order to be sure that the needs of public health will be appropriately represented, both in terms of data collection and of requirement for analysis. Such a machinery does not exist in many countries I know of.

A further problem is the paucity of research in the field of information system, which corresponds to a lack of interest in the academic public health Except for the management of health services (where information is a flourishing market), public health has not produced recently many new ideas on routine statistics. Consider for example the registration of cause of death, a remarkable epidemiological tool implemented and developed during the past century in the emerging modern states. ${ }^{3}$ Using death as an official event with compulsory registration, the cause of the death was registered and analysed as a surrogate for disease. This has provided enormous contribution to the field of public health, from the monitoring of the population health to the evaluation of the impact of public health interventions.

However, causes of death are notoriously inadequate to capture the health status of an aged or very aged population: doctors have to choose a "causal" disease among two or three serious conditions, among 10 known pathologies. One consequence is that causes of death tend to be ignored when this population is analysed despite the fact that people aged more than 60 provide $80 \%$ of the deaths in developed countries. A more sensible approach would be to develop novel approaches for the use of death in health statistics: an option would be to measure prevalent diseases at death.

Another area where research is lacking is the systematic analysis of the impact of information system on decision in public health. As pointed out by Unal et al, the health system requires "good evidence, particularly as resources are limited". However, it is difficult to find good systematic reviews showing how the information provided by routine statistics has been conclusive to start, to modify or to stop a public health strategy. Of special interest for systematic research is the way public health professionals interpret observed trends from routine statistics in term of proof or decisive argument (see for example the debate about the impact of the control of cardiovascular risk factors ${ }^{4}$ ). Unlike clinical medicine, where the development of evidence based guidelines triggered off several research lines to analyse the impact of information on doctors' activities, public health has been slow to develop an interest in this field.

Addressing these three points, and several others, requires an active involvement of each practitioner and researcher. Routine statistics are an important resource for public health, but are yet underresearched and underfunded: as stated by Unal and colleagues, the 2 billion spent annually by the NHS to take care of CHD patients does not have a reasonable counterpart in terms of investment in the information system. As a matter of fact, routine statistics have been a prerequisite for the development of the modern public health. The future of public health also depends on the professional willingness to maintain these resources.

$J$ Epidemiol Community Health 2003;57:476-477 


\author{
Author's affiliations \\ F Paccaud, Institute of Social and Preventive \\ Medicine, IUMSP Bugnon 17, Lausanne, \\ Switzerland \\ Correspondence to: Professor F Paccaud; \\ paccaud@inst.hospvd.cg
}

\section{REFERENCES}

1 World Health Organisation. The World Health Report 2000 Health Systems: improving performance. Geneva: WHO 2000. http://www.who.int/whr2001/2001/ archives/2000/en/contents.htm (accessed 15 Jan 2003).

2 Unal B, Critchely JA, Capewell S. Missing, mediocre, or merely obsolete? An evaluation of UK data sources for coronary heart disease. J Epidemiol Community Health 2003:57:530-5.

3 Le Bras H. Naissance de la mortalité : l'origine politique de la statistique et de la démographie. Paris: Gallimard/ Le Seuil, 2000

4 Ebrahim S, Davey Smith G. Exporting failure? Coronary heart disease and stroke in developing countries. Int J Epidemiol 2001;30:201-5, 1493-7.

\section{Determinism versus stochasticism: in support of long coffee breaks}

\section{C Tam, B A Lopman}

\section{Is there a recipe for the causal pie?}

c $\mathrm{n}$ his recent article describing what characterises a useful concept of causation in epidemiology, ${ }^{1}$ Olsen provides a useful overview of the now popular component-cause model and its relevance for epidemiological research, and renews the call for discussion on how best to conceptualise causation. As he rightly points out, this is not merely of academic interest - how we view causation influences (whether consciously or not) the way in which we frame research questions and analyse and interpret epidemiological data. In recent decades, the component-cause model has been the predominant causal framework on which epidemiological research has been based, and it has been of great use for the identification of individual risk factors associated with disease and the development of the advanced statistical techniques that are now widely used for this purpose. Based on these successes, Olsen argues for the usefulness of the component-cause model over more recently propounded frameworks based on a probabilistic view of causality. ${ }^{23}$ In doing so, however, we feel he is rather hasty in accepting a deterministic future for epidemiology.

The great value of the componentcause model lies in its heuristic power. A person, through exposure to various risk factors, eventually accumulates a combination of contributing exposures that constitute a "sufficient cause" and that, under identical conditions, invariably lead to disease. As visualised by Rothman and Greenland, ${ }^{4}$ these contributing exposures, or "component causes", form the slices of a "causal pie" that, when complete, constitute a "sufficient cause". This deterministic model provides a useful framework with which to conceptualise causation in a chronological manner, from first exposure to a component cause all the way to the completion of the "causal pie" and subsequent disease. It is here, however, that the componentcause model faces its greatest problem. Epidemiology is a population science and, while it may have the ability to explain differences in disease risk or exposure distribution between groups of individuals, it cannot provide causal explanations for any single one of those individuals. That a person smokes, drinks, has a diet rich in saturated fats, and subsequently develops coronary heart disease does not demonstrably mean that any of these factors or their combination was the "cause" of their illness. Thus, the "black box" that Olsen attributes to models based on probabilistic thinking applies equally to the deterministic approach.

Olsen describes probabilistic models as minimalist and purely statistical, in which causes merely increase the probability of disease and preventable factors decrease it-"what you see is what you get". We disagree that a probabilistic model need necessarily be entirely descriptive. The causal criteria of effect magnitude, consistency, temporality, biological plausibility, and dose response are equally applicable to probabilistic frameworks, and Olsen himself acknowledges that the latter is not easily incorporated into the component-cause model. Nor do we think that the component-cause model has greater explanatory power. The fact that exposures are termed "component causes" is an admission that they only serve to increase the probability of disease and need not be a "cause" unless they are in themselves sufficient. This merely obscures the probabilistic view, as held by Parascandola and Weed, of causes as factors that increase the probability of disease and where "a sufficient cause is ... one that raises the probability of its effect occurring to 1 , and a necessary cause raises the probability from $0 .{ }^{\prime \prime 3}$

In addition, Olsen perceives problems for probabilistic models in terms of risk communication:

\footnotetext{
"At present we tell a smoker that he will increase his risk of getting lung cancer 10-fold by smoking. If he gets lung cancer from smoking, it will take decades to develop, and he may even get lung cancer, should he decide not to smoke at all."
}

His view that this statement "is in conflict with a common sense understanding of causation, and it is apparently not very convincing" may be true, but the statement is also realistic. To pretend that we can make more elaborate predictions of disease at the individual level is to make rather immodest claims of our understanding of causation.

Olsen is right to emphasise that our view of causation influences the way in which we conduct research. In this respect, the component-cause model has tended to individualise epidemiology, an opinion that has been extensively commented on by others. ${ }^{5-8}$ The component-cause model was borne out of an era in which infectious diseases, with their singular causal pathways (a single infectious agent as a "necessary" factor for disease), ceased to be (for a notable minority and rather prematurely) the major concern and novel causal frameworks were necessary for the new challenges of non-infectious diseases. The realisation that this second group of diseases could be linked to a whole plethora of exposures meant that a new way of thinking was needed in which all these could be investigated and incorporated into a theory of causation. In attempting to determine why some people become diseased while others do not, epidemiological inquiries were directed at differences in lifestyle between individuals, in the belief that changes in personal behaviour would lead to a decrease in exposure and disease risk, and with the assumption that such behavioural change was possible. The premise was simple: through 
their behaviour, people become exposed to a certain combination of factors that act independently or synergistically, or both, to cause disease. This framework is essentially mechanistic-it entails identifying the steps, the serial accumulation of component causes, that eventually lead to illness. We therefore contest Olsen's assertion that "[t]he component-cause model attempts to explain why" disease occurs. The model does not answer the question of why people become diseased, but rather how-what processes are involved in "causing" their illness. In fact, we argue that much of what is commonly referred to as "risk factor epidemiology" is a discipline in which the question "why" has conveniently been replaced by the more readily accessible "how". If epidemiology is to be explanatory rather than descriptive in its inquiry and proactive rather than reactive in its application, causal frameworks that will provide insights into the underlying factors that influence these biological processes are needed.

This is not to decry the successes of such epidemiological research. We now know a great deal about individual factors associated with non-infectious diseases, most notably cancer and coronary heart disease. The continued emphasis on this kind of individualistic inquiry is much disputed, however, as illustrated by a recent series of commentaries on the search for risk factors for coronary heart disease. ${ }^{9-14}$ Moreover, the component-cause view has spawned an era of epidemiology characterised by drug dependency and the promotion of expensive therapies that will most likely be inaccessible to those in lower income countries who, by current projections, will increasingly bear the brunt of the non-infectious disease epidemics in the coming decades. ${ }^{15}$ The contribution of risk factor epidemiology to the victimisation of individuals has also been commented on, particularly by Farmer, who speaks of the "exaggeration of personal agency"16 - the assumption that behavioural change alone is a realistic intervention given the strong cultural, social and economic forces that are exerted on individuals.

The answer to the question of why some individuals become diseased while others do not then, lies further upstream and requires investigation of the factors affecting a person's daily life choices (or lack thereof). This concept was recognised by Rose, who differentiated between "the causes of cases and the causes of incidence".$^{781718}$ Krieger has expanded upon this notion, arguing that differences in disease distribution are "mutable and embodied biological expressions $^{\prime 19}$ of social inequity and injustice. The component-cause model is based on the premise of a sufficient cause that, all else being equal, will invariably lead to disease in individuals. The fact is that all else is hardly ever equal. Simply looking at differences between decontextualised groups of individuals can lead to what could be termed "outcome bias", a failure to recognise that disease distributions in different populations can be affected by a whole host of social factors that influence individual risk. The growing epidemic of childhood obesity provides a good example of this. Although linked to an imbalance between energy intake and expenditure in both higher and lower income countries, a full understanding of why opposite socioeconomic groups are predominantly affected in these two settings is not possible without taking into consideration factors such as local food production, global food trade, marketing of foodstuffs, and social changes leading to decreased physical activity, all of which affect choice, accessibility, and individual risk.

In arguing for a broader scope of epidemiological inquiry we do not intend to favour stochasticism over determinism. We consider this issue to be part (perhaps a small part) of a wider discussion on what epidemiologists regard as being causal and mutable and, therefore, within the scope of epidemiology. It is probable that both views will encounter problems in incorporating the multiple levels required to understand disease causation, and ultimately neither may fully succeed. We thus agree with McPherson's view that "[i]t is high time that public health stopped behaving as if one single dominant paradigm was good enough." Restricting our perspective of causation based on the past successes of a model grounded largely in a biomedical view of health will prevent us from exploring alternative frameworks and will not suffice to further our understanding of disease determinants. Developing new frameworks of causation will be crucial for expanding the boundaries of epidemiology and liberating the field from the confines of individualism. As Karhausen's Epimenides eloquently concludes, "the cause of a disease 'is the handle, so to speak, by which human beings can manipulate it."' 2 The question now is what we view as having handles that can be manipulated. This discussion will run for as long as epidemiologists roam the Earth and so we welcome Olsen's call for a more open debate. Olsen himself has been quoted as saying that "[t]he view [of causation] we adopt has consequences which reach far beyond informal discussion during coffee breaks." ${ }^{3}$ We can only hope for longer coffee breaks.

\section{ACKNOWLEDGEMENTS}

The authors thank Dr Laura C Rodrigues for helpful comments on the manuscript.

$J$ Epidemiol Community Health 2003;57:477-478

\section{Authors' affiliations}

C C Tam, Infectious Disease Epidemiology Unit, Department of Infectious and Tropical Diseases, London School of Hygiene and Tropical Medicine, London, UK

C C Tam, B A Lopman, Gastrointestinal Diseases Division, Communicable Disease Surveillance Centre, London, UK

Correspondence to: Mr C C Tam, Gastrointestinal Diseases Division Communicable Disease Surveillance Centre, 61 Colindale Avenue, London NW9 5EQ, UK: clarence.tam@lshtm.ac.uk

Accepted for publication 18 March 2003

\section{REFERENCES}

1 Olsen J. What characterises a useful concept of causation in epidemiology? J Epidemiol Community Health 2003:57:86-8.

2 Karhausen LR. Causation in epidemiology: a Socratic dialogue: Plato. Int J Epidemiol 2001;30:704-6.

3 Parascandola M, Weed DL. Causation in epidemiology. J Epidemiol Community Health 2001;55:905-12.

4 Rothman KJ, Greenland S. Modern epidemiology. Philadelphia: Lippincott Williams and Wilkins, 1998.

5 Krieger N. Epidemiology and the web of causation: has anyone seen the spider? Soc Sci Med 1994;39:887-903.

6 Susser M, Susser E. Choosing a future for epidemiology: II. From black box to Chinese boxes and eco-epidemiology. Am J Public Health 1996;86:674-7

7 McMichael AJ. Prisoners of the proximate: loosening the constraints on epidemiology in an age of change. Am J Epidemiol 1999;149:887-97.

8 Rockhill B. The privatization of risk. Am J Public Health 2001;91:365-8.

9 Beaglehole R, Magnus P. The search for new risk factors for coronary heart disease: occupational therapy for epidemiologists? Int J Epidemiol 2002;31:1117-22

10 Marmot M. Occupational therapy or the major challenge? Int J Epidemiol 2002;31:1122-4.

11 Nieto F. The epidemiology of self-deprecation. Int J Epidemiol 2002;31:1124-7.

12 Law C. Using research evidence to promote cardiovascular health in children. Int J Epidemiol 2002;31:1127-9.

13 Greenland P, Gidding SS, Tracy RP. Lifelong prevention of atherosclerosis: the critical importance of major risk factor exposures. Int J Epidemiol 2002;31:1129-34

14 Beaglehole R, Magnus P. Coronary heart disease prevention: act now, research at leisure. Int J Epidemiol 2002;31:1134-5.

15 World Health Organisation. World Health Report 2002: reducing risks, promoting healthy life. Geneva: WHO, 2002

16 Farmer P. Infections and inequalities: the modern plagues. Los Angeles: University of California Press, 1999.

17 Rose G. Sick individuals and sick populations. Int J Epidemiol 1985;14:32-8.

18 Marmot M. Economic and social determinants of disease. Bull World Health Organ 2001;79:988-9.

19 Krieger N. Theories for social epidemiology in the 21 st century: an ecosocial perspective. Int J Epidemiol 2001;30:668-77. 